\title{
Influence of Goal Orientation on Players' Performance with Special Reference to Sri Lanka National Team Sports
}

\author{
Perera HPN ${ }^{1, *}$, Jusoh $\mathbf{M}^{2}$, Azam SMF ${ }^{2}$, Sudasinghe SRSN ${ }^{3}$ \\ ${ }^{1}$ Department of Sport Science, Faculty of Applied Sciences, University of Sri Jayewardenepura, Sri Lanka \\ ${ }^{2}$ Graduate School of Management, Postgraduate Centre (PGC), Management and Science University (MSU), Malaysia \\ ${ }^{3}$ Sri Lanka Institute of Development Administration, Sri Lanka
}

Received August 6, 2019; Revised December 2, 2019; Accepted December 4, 2019

Copyright $\bigcirc 2019$ by authors, all rights reserved. Authors agree that this article remains permanently open access under the terms of the Creative Commons Attribution License 4.0 International License

\begin{abstract}
The purpose of the present research was to study the relationship between goal orientation and performance in team sports players. The Task and Ego Orientation in Sport Questionnaire (TEOSQ) was used for the assessment of goals. The observed variable of the study was perceived performance and was measured through a likert scale questionnaire, which had been adopted from literature. Subjective performances of the players were considered. Data was collected from Sri Lankan national team players who are engaged in team sports of football, basketball, Elle, volleyball, Hockey, Kabaddi, Netball, Rugby and Throw ball. The study population was 308 national team players and the universal sampling technique was used. Data were analyzed using SPSS and structural equation modeling with AMOS. The study results reveal that there is a significant association between goal orientation and performance of the players while a significant relationship exists between task orientation and performance. A moderate level of association was derived from ego orientation which in turn leads to performance.
\end{abstract}

Keywords Goal Orientation, Perceived Performance, Ego Orientation, Task Orientation, Subjective Performance

\section{Introduction}

Anecdotal evidence and the media have suggested that many athletes are preoccupied with the outcome of competitive events. Sports in many cases are achievement-oriented. Players give their foremost concentration to succeed in any event. Goal setting and goal orientation are the most important paradigms that affect the motivation of individuals to achieve and to excel in tasks in which they are engaged in (Tenenbaum, Spence, \& Christensen, 1999; Prager, 2016).

Sri Lanka is a developing nation in Asian region and had suffered with a civil war for more than 30 years. Goal orientation concept was practiced by politicians, government officials and administrators to address post war shocks. The mere attention with regard to goal orientation should be diluted to every single aspect of the society to gain maximum benefits or performance of the resources including individuals (Biyanwila \& Perera, 2018).

Performances of Sri Lanka national team sports are not pleasing at all in international context during the history of sports. There are countless types of factors affecting the performance of the players. Out of these factors, a special recognition goes to the goal orientation construct (Duda \& Nicholls, 1992). This study is directed at investigating the influence of goal orientation on national level team players performance in Sri Lanka. There is a dearth of literature in this regard in Sri Lanka context (Perera \& Pushpakumari, 2016; Somaratne, Nugaliyadda, Sagarika, Amarasinghe, Kahadawarachchi, \& Thelijjagada, 2014; Perera, Jusoh, Azam, \& Sudasinghe, 2019). Therefore the main purpose of this research is to analyze the relationship between goal orientation and performance of the players who represent the national team sports in Sri Lanka during 2018.

\section{Literature Review}

Goal orientations were initially defined as "situated orientations for action in an achievement task" (Ames, 1992; Nicholls, 1984). It was then defined as why and how people are attempting to attain different objectives and referred to predominant purposes of achievement behavior. The foremost focus of the latter definition was given on the content of what people are attempting to achieve more 
likely the objectives and/or specific standards (Kaplan \& Maehr, 2007). Scholars have described goal orientation as a to a certain extent stable individual difference factor that can be altered by situational factors (Button, Mathieu, \& Zajac, 1996).

In addition, studies in relation to goal orientation has discovered favorable effects for state learning and state performance goals in which the goals persuaded by situational indications, on task performance, contingent on the nature of the task (Heintz, Steele-Johnson, \& Narayan, 2002; Heintz \& Steele-Johnson, 2004).

Different scholars have provided goal orientation definitions based on the way that people may adopt in achievement situations (Pintrich, 2000). Based on these differences, most researchers concentrated mostly on two-fold main orientations which can be found in relation to adaptive and maladaptive engagement (Kaplan \& Maehr, 2007). According to Ames (1992) there appears a convergence among scholars on these two orientations and labeled these as "mastery" and "performance" goals.

Elliot and McGregor (2001), in their four factors model of goal orientation hypothesized that competence is at the foundation of achievement goals. The two primary dimensions, which the four factors are formed along, are based on definition of competence (mastery/performance) and valence of competence (approach/avoid) (Elliot \& McGregor, 2001). Both dimensions are fundamental components of individuals' self-regulatory performance focused toward the reaching of achievement goals.

The literature relating to achievement motivation backed by achievement goal inquiry proposes that the responses can be divided into two global perceptions specifically, task orientation and ego orientation (Duda, Motivation in sports setting: A global perspective approach, 1992). Task Orientation is self-referenced and it entails an emphasis on gaining skill and performing one's best. An ego-oriented player, on the other hand, demonstrates a normative commencement of ability and skills and the main concern will be given by them to establish superiority over others, which entails with social comparison (Willam, 1994).The two concepts are distinguished based on achievement behavior. Previous studies reported that both the dimensions to be independent (Duda \& Whitehead, 1998; Roberts, Treasure, \& Kavussanu, 1996)whilst generalized across different achievement domains (Duda \& Nicholls, 1992).

Early goal orientation research work had been conducted in educational domain, and these goals are assumed to be a directing force which in turn affects both cognitive and affective responses to achievement events (Duda, Fox, \& Armstrong, 1992). It was furthermore, suggested that students' feelings, thoughts and behavior are rational expressions of their dominant goals (Nicholls, 1989)and furthermore explained that the personal goals of task and ego are central components of students' academic achievement and personal theories. Nicholls et al. (1985), found a regular relationship among goal orientations and beliefs about the academic setting. Ego orientation was associated with beliefs which emphasis that the success is the product of superior ability and of beating peers. A task orientation was related to beliefs that success is the outcome of effort, cooperation with peers, and trying to comprehend classroom materials (Lochbaum \& Roberts, 1993).

Research in sports at early stages during 1980's had found that task and ego orientation are relevant and meaningful in the context under consideration. It was furthermore found that the rational interrelationships between goals and beliefs that have emphasized in class room also exit in sports (Duda \& Nicholls, 1992).

There are few theories which nourish the goal orientation construct. Achievement Goal Theory (AGT) is one of the cognitive theories which psychologists had paid their special attention. AGT is a psychological theory of intrinsic motivation that considers how beliefs and cognitions orient us towards achievement or success, especially in relation to two styles, task (mastery) and ego (performance). The credit of development of this theory goes to John Nicholls and according to this theory, the success and failure may depend on athlete's perception of whether he or she has reached his or her personal goal. The principle emphasis in AGT is that, each person is goal-oriented and wishes to prove his skills and competencies (Nicholls, 1984).

The other key construct of this research is the performance of the players. Performance measurement is with two folds, namely subjective and objective (Perera, Jusoh, Azam, \& Sudasinghe, 2019).Objective measures considered the actual performance which would be measured through win loss percentages, points accumulated in a medal table and many more (Vella, Oades, \& Crowe, 2013; Perera, 2018; Perera \& Pushpakumari, 2015; Carron, Bray, \& Eya, 2002; Hollings, Hopkins, \& Hume, 2012; Perera \& Pushpakumari, 2015). Subjective performance is measured by considering the perception of the players, coaches or spectator's performance (Besharat \& Pourbohlool, 2011; Perera \& Pushpakumari, 2016). Since it was hard to assess objective performance due to poor performance records of Sri Lankan team sports at international context, the main attention was given to the subjective performance which considered the players perception on their performance. Sri Lanka performance records of Olympic, Asian and South Asian games are counted to be very nominal. Therefore, tabulation of team sports performance in this regard was not viable and it had led the researcher to consider the subjective performance.

\section{Materials and Methods}

\subsection{Population and Sample}

The total population under consideration was 308 male and female team players who represent Sri Lanka National team sports in 2018/2019. Census sampling technique was 
used and the questionnaires were distributed among the total population. The descriptive statistics are as follows.

Table 1. Descriptive Statistics the total usable questionnaires were counted as 308

\begin{tabular}{|c|c|c|c|}
\hline Variable & Frequency & Percentage & Mean \pm SD \\
\hline Gender & & & \\
\hline Male & 179 & $58.1 \%$ & \\
\hline Female & 129 & $41.9 \%$ & \\
\hline Your Involved Sport & & & \\
\hline Basketball & 26 & $8.4 \%$ & \\
\hline Cricket & 13 & $4.2 \%$ & \\
\hline Elle & 18 & $5.8 \%$ & \\
\hline Football & 60 & $19.5 \%$ & \\
\hline Hockey & 40 & $13 \%$ & \\
\hline Kabaddi & 42 & $13.6 \%$ & \\
\hline Netball & 20 & $6.5 \%$ & \\
\hline Rugby & 28 & $9.1 \%$ & \\
\hline Volleyball & 43 & $14.0 \%$ & \\
\hline Throw ball & 18 & $5.8 \%$ & \\
\hline Age & & & $25.2 \pm 4.3$ \\
\hline
\end{tabular}

According to Table 1, most participants were male (58.1\%) and female participants were $41.9 \%$ out of total sample. Most of the players were from Kabaddi (13.6\%). The average age of a player was 25.2 with a standard deviation of 4.3 .

\subsection{Data Collection}

Questionnaire was used to collect data from the players to measure the goal orientation and performance. Task and Ego Orientation in Sport Questionnaire (TEOSQ) developed by Duda (1998) was used to measure the goal orientation while the measure for perceived performance of players was adopted from Lemmink et.al (2008).
The orthogonal stability of the TEOSQ has been earlier validated (Duda \& Nicholls, 1992; Duda, Fox, \& Armstrong, 1992)in Western Nations. TEOSQ has demonstrated high internal consistency according to the said authors. The Cronbach's alpha coefficients of the present study for TEOSQ and perceived performance facets were .823 and .93 , respectively, which is higher than the cutoff value suggested by Nunnally (1978).

Based on the Literature and theoretical foundation three hypotheses were examined.

Hypothesis $1\left(\mathrm{H}_{1}\right)$ : There is a significant relationship between goal orientation and performance of the players

Hypothesis 1a $\left(\mathrm{H}_{1 \mathrm{a}}\right)$ : There is a significant impact of task orientation on performance of the Players

Hypothesis $1 \mathrm{~b}\left(\mathrm{H}_{\mathrm{b}}\right)$ : There is a significant impact of ego orientation on performance of the Players

The reliability and validity of measurement model were tested with item reliability, internal consistency and discriminant validity. Factor loading analysis was conducted as the initial step. It is recommended that the Standardized factor loading must be more than 0.5 (Argyris \& Schön, 1997).

Table 2 depicts the results of the Confirmatory Factor Analysis (CFA). Convergent validity was measured through Average Variance Extracted (AVE).

Table 2, also depicts the factor loading figures and items which are below 0.5 were removed as per the specifications of Hair et.al (2006). Therefore it can be concluded that, survey instrument is reliable to measure each constructs in the model. Cronbach's Alpha of reliability testing in this study was above 0.7 . According to Nunnally \& Bernstein (1994), the adequate values of alpha, ranging from 0.70 to 0.95 . Hence, it can be concluded that the items are reliable to proceed with the questionnaire.

Table 2. CFA of Measurement Model

\begin{tabular}{|c|c|c|c|c|c|}
\hline Construct & Item & Standardized Factor Loading $(>0.5)$ & $\operatorname{AVE}(>0.5)$ & $\mathrm{CR}(>0.6)$ & Cronbatch’s Alpha(>0.7) \\
\hline \multirow{5}{*}{ GO-Task } & GO1 & Removed & \multirow{5}{*}{0.372} & \multirow{5}{*}{0.69} & \multirow{5}{*}{0.823} \\
\hline & GO2 & 0.65 & & & \\
\hline & GO4 & 0.53 & & & \\
\hline & GO6 & 0.78 & & & \\
\hline & GO7 & Removed & & & \\
\hline \multirow{3}{*}{ GO-Ego } & GO3 & 0.63 & \multirow{3}{*}{0.411} & \multirow{3}{*}{0.63} & \multirow{3}{*}{0.82} \\
\hline & GO5 & 0.68 & & & \\
\hline & GO8 & 0.48 & & & \\
\hline \multirow{6}{*}{ Performance } & PE1 & 0.52 & \multirow{6}{*}{0.504} & \multirow{6}{*}{0.831} & \multirow{6}{*}{0.93} \\
\hline & PE2 & 0.78 & & & \\
\hline & PE3 & 0.85 & & & \\
\hline & PE4 & 0.68 & & & \\
\hline & PE5 & Removed & & & \\
\hline & PE6 & 0.67 & & & \\
\hline
\end{tabular}


AVE is calculated as the mean variance extracted for the items loading on a construct and is a summary indicator of convergence (Fornell \& Larcker, 1981). An AVE of 0.5 or greater is a good rule of thumb signifying sufficient convergence and AVE of less than 0.5 specifies that, on average, more error remains in the items than variance explained by the latent factor structure imposed on the measure. As per to table few of the constructs are lack of convergence. Fornell and Larcker (1981) have recommended that CR must be higher than 0.6 if the AVE is less than 0.5 , to support the acceptance of a factor model (Fornell \& Larcker, 1981; AlMenhali, Khalid, \& Iyanna, 2018).

\section{Results and Discussion}

The relationships between goal orientation and perceptions of performance of the players were analyzed using a Structural Equation Modeling procedure. Goodness of fit is the foremost output that can be extracted from the first phase of SEM data analysis. Chi-square statistics (CMIN), comparative fit index (CFI), root mean square error of approximation (RMSEA)Tucker Lewis index (TLI), relative fit index (RFI), incremental fit index (IFI), and the goodness of fit index (GFI) are the most important fit indices that should be examined (Hair, Black, Babin, \& \& Anderson, 2010).

Perceived performance latent variable is defined by six indicators. Since the initial model did not matched with the pre requisites of modification indices PE5 was removed. CR value for multivariate Kurtosis between PE5 and PE6 was reported to be 34.460 . After removing PE5, the model correctness was achieved.

Table 3. Model fitting analysis for primary and modified measurement models of Goal Orientation

\begin{tabular}{|c|c|c|c|}
\hline Fit Index & $\begin{array}{c}\text { Primary } \\
\text { Model }\end{array}$ & $\begin{array}{c}\text { Critical } \\
\text { (Acceptable) } \\
\text { Value }\end{array}$ & $\begin{array}{c}\text { Modified } \\
\text { Model }\end{array}$ \\
\hline $\begin{array}{c}\text { Comparative Fit Index } \\
\text { (CFI) }\end{array}$ & 0.815 & $>0.9$ & 0.975 \\
\hline $\begin{array}{c}\text { Tucker Lewis Index } \\
\text { (TLI) }\end{array}$ & 0.728 & $>0.9$ & 0.953 \\
\hline $\begin{array}{c}\text { Normed Chi Square } \\
\text { (Chi/Df) }\end{array}$ & 6.378 & $<0.3$ & 2.150 \\
\hline $\begin{array}{c}\text { Root Mean Square } \\
\text { Error of } \\
\text { Approximation } \\
\text { (RMSEA) }\end{array}$ & 0.132 & $<0.085$ & 0.061 \\
\hline \multicolumn{2}{|c|}{} & & \\
\hline
\end{tabular}

\subsection{Measurement Model}

The measurement model was derived after conducting CFA and the model depicts in Figure 1 ensures that it had matched all the modification indices and hence model correctness was achieved. Therefore, the measurement model itself was considered as the final model for further analysis.

Table 4 depicts the summary of modification indices to assess whether the model is fit enough for further analysis.

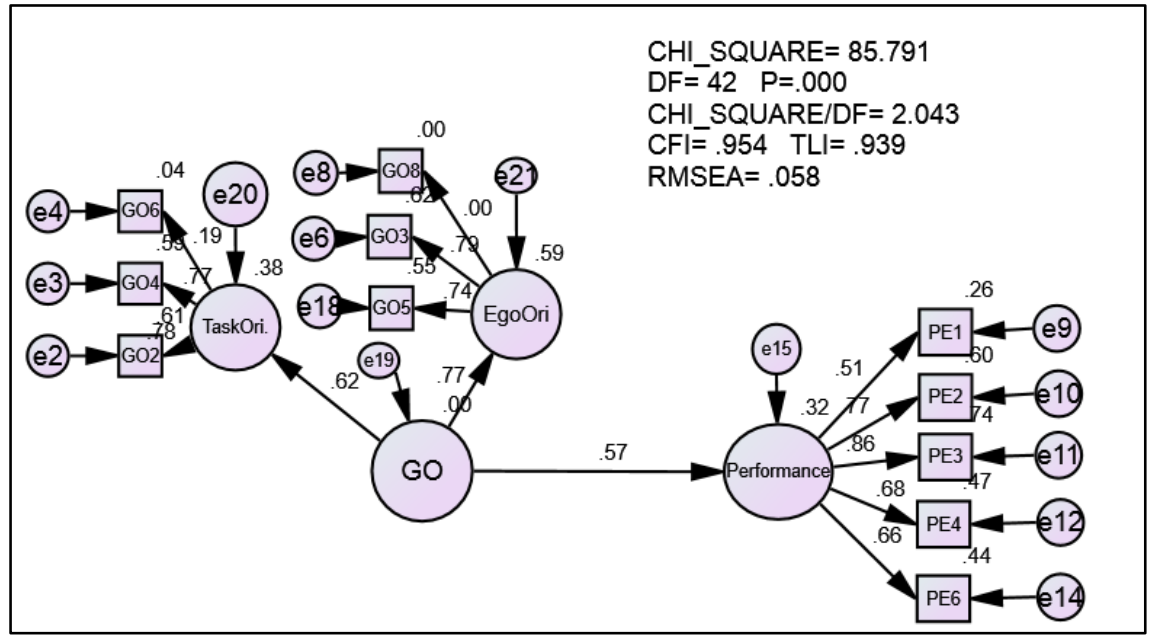

Figure 1. Model - Exhibit the relationship between Goal orientation and Performance

Table 4. Model fitting analysis for measurement models of Goal Orientation and performance relationship

\begin{tabular}{|c|c|c|c|}
\hline Fit Index & Primary Model & Critical (Acceptable) Value & \multirow{2}{*}{ Modification Requirement } \\
\hline Comparative Fit Index (CFI) & 0.954 & $>0.9$ & \multirow{2}{*}{ Model is considered as accepted } \\
\cline { 1 - 2 } Tucker Lewis Index (TLI) & 0.939 & $<0.9$ & \\
\hline Normed Chi Square (Chi/Df) & 2.043 & $<0.3$ & \\
\hline $\begin{array}{c}\text { Root Mean Square Error Of } \\
\text { Approximation (RMSEA) }\end{array}$ & 0.058 & $<085$ & \\
\hline
\end{tabular}




\subsection{Structural Model}

Structural modeling is applied next to identify the hypothesized connection among research constructs (exogenous or endogenous), which is linked to the assumed model's concept.

Hypothesis 1 (H1): There is a significant relationship between goal orientation and performance of the players

The first Hypothesis is tested based on Figure 2, to examine whether Goal Orientation (GO) of the players as the exogenous variable is related to players Performance (P) which is the endogenous variable in this study. This relation of GO with performance exhibits perfect model fit to the given data $[\mathrm{CFI}]=0.954$, $[\mathrm{TLI}]=0.939$, $[\mathrm{Chi} \mathrm{squ} / \mathrm{df}]$ $=2.043$, and $[$ RMSEA $]=0.058$ ). As presented in Figure 2, goal orientation has a significant positive impact on player's performance $(\mathrm{b}=0.493$; $\mathrm{p}$-value $<0.05)$. Therefore, players perceived that they get higher performance with higher goal orientation.

Hypothesis 1a (H1a) : There is a significant impact of task orientation on performance of the Players

The second Hypothesis is tested to investigate whether Task orientation which is one of the constructs of Goal orientation is directly related to performance of the players. This relation presents acceptable model fit to the given data $[\mathrm{CFI}]=0.989$, $[\mathrm{TLI}]=0.984$, $[$ Chi squ/df $]=1.435$, and $[$ RMSEA] $=0.038$ ). Figure 4 shows the impact of a latent variable over a measurement variable, which is one of the features of SEM techniques for modeling. As seen in Figure 3, Task orientation has a significant positive impact on performance of the players ( $b=0.636$; $p$-value $<0.05$ ). Therefore, players perceive that task orientation leads to higher performance.

Hypothesis $1 \mathrm{~b}(\mathrm{H} 1 \mathrm{~b}) \quad$ : There is a significant impact of ego orientation on performance of the players

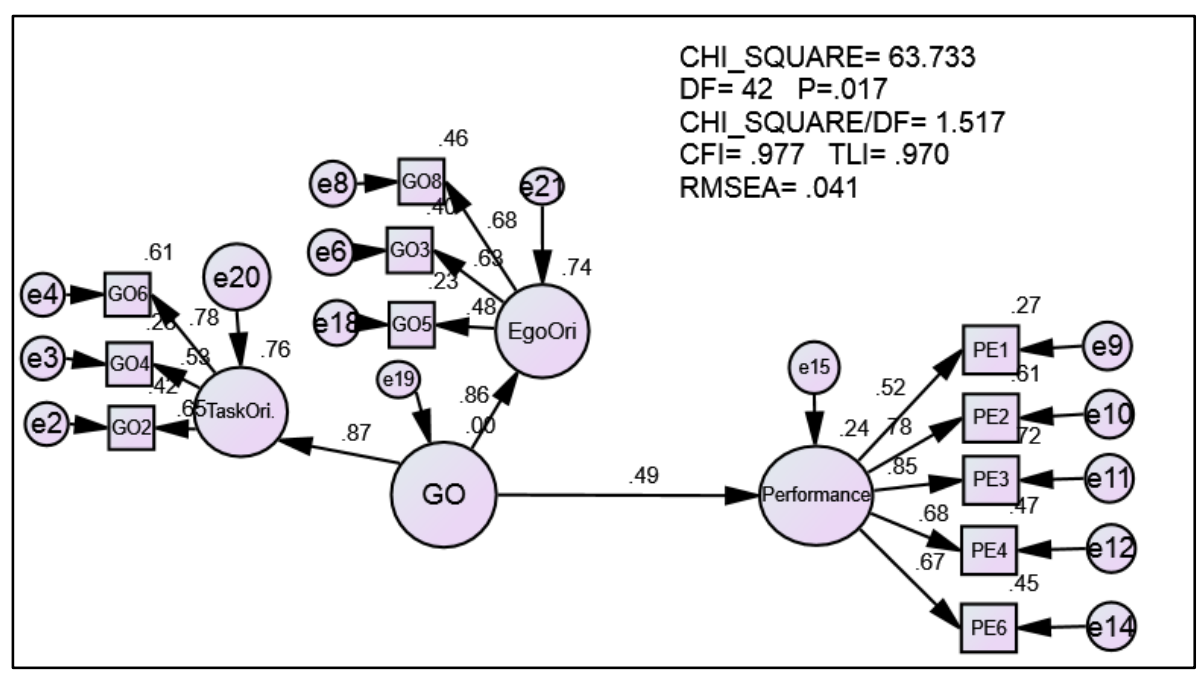

Figure 2. Structural Model - H1

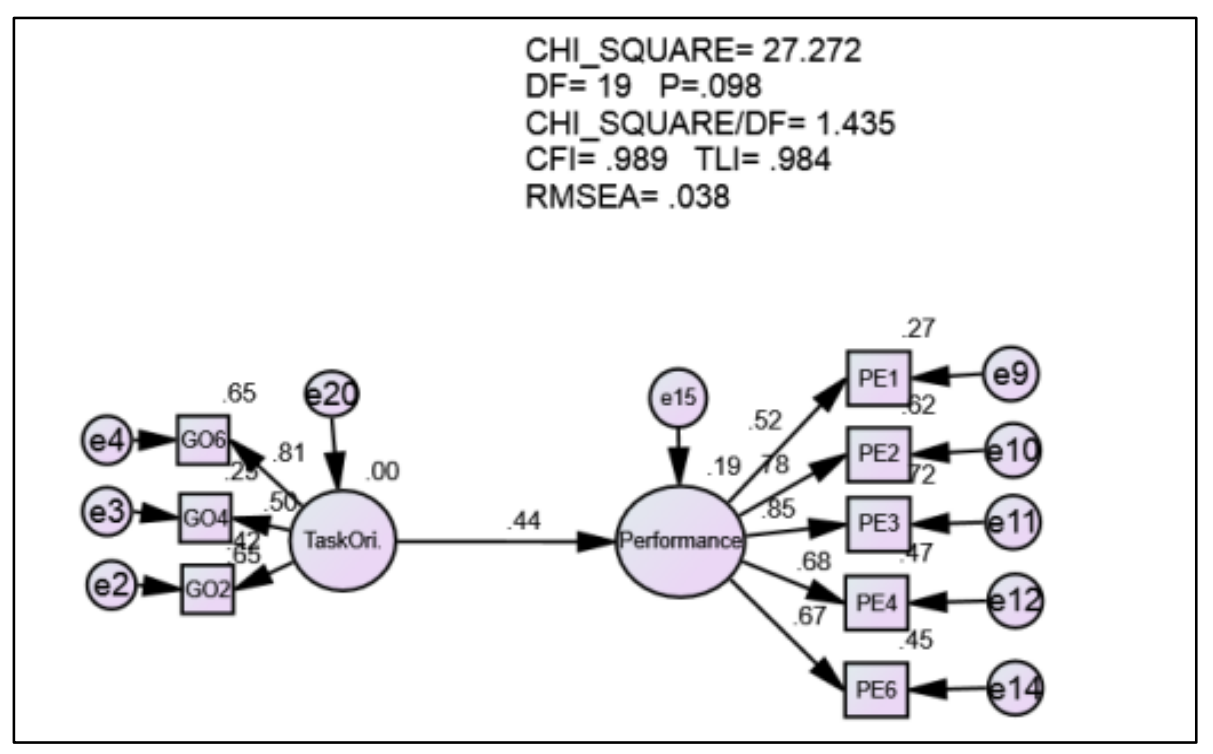

Figure 3. Structural Model - H1a 


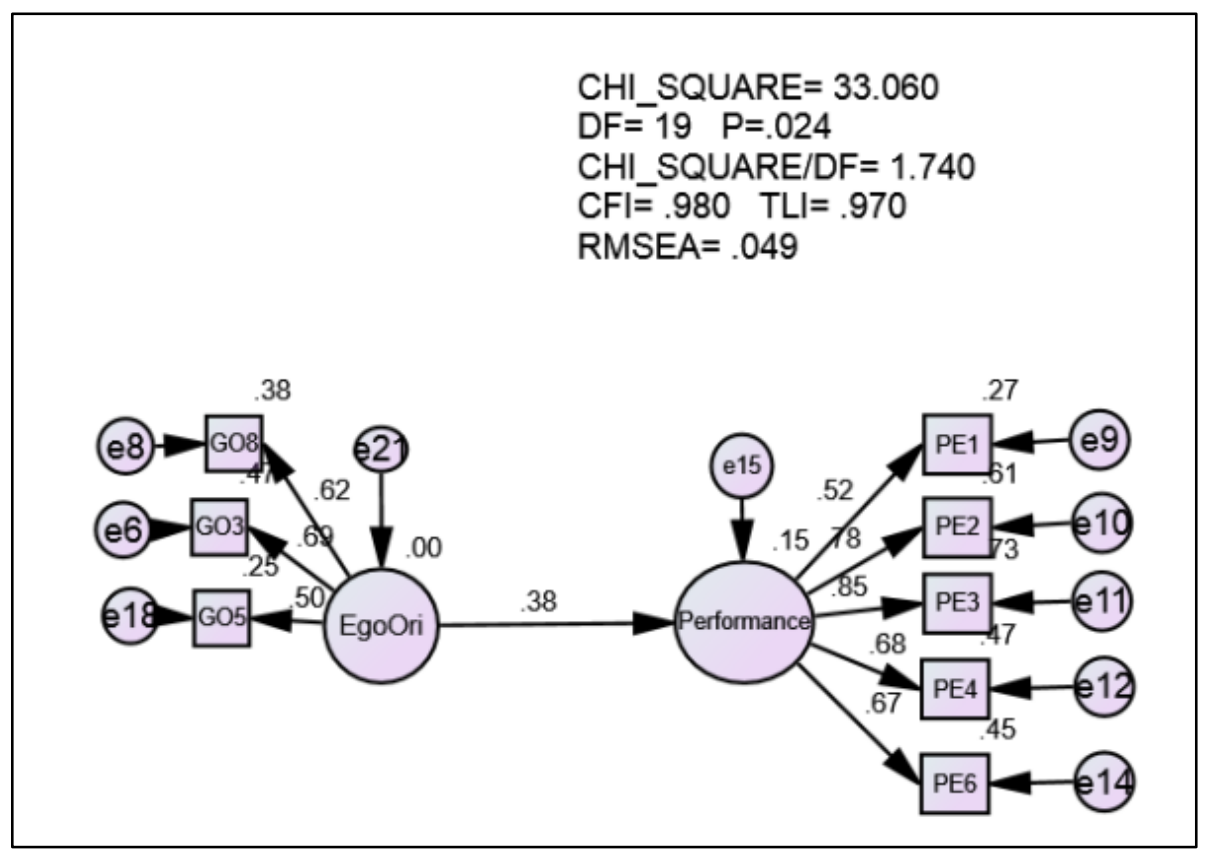

Figure 4. Structural Model $-\mathrm{H} 1 \mathrm{~b}$

The third hypothesis is tested based on Figure 4, to investigate whether Ego orientation which is one of the constructs of Goal orientation is directly related to performance of the players. This relation presents acceptable model fit to the given data $[\mathrm{CFI}]=0.980$, $[\mathrm{TLI}]$ $=0.970$, $[$ Chi squ/df $]=1.740$, and $[$ RMSEA $]=0.049)$. As seen in Figure 4, Ego orientation has a positive but weak impact on performance of the players ( $b=0.683$; $\mathrm{p}$-value $<$ 0.05). Therefore, players perceive that ego orientation moderately leads to higher performance. Table 5, illustrates the summary of the Relationships.

Table 5. Summary of the Results of the Structural Model

\begin{tabular}{|c|c|c|c|}
\hline Hypothesis & Relationship & B Value & p-value \\
\hline $\mathrm{H} 1$ & GO $\rightarrow$ PE & 0.493 & 0.017 \\
\hline $\mathrm{H} 1_{\mathrm{a}}$ & TASK $\rightarrow \mathrm{PE}$ & 0.636 & 0.098 \\
\hline $\mathrm{H} 1_{\mathrm{b}}$ & $\mathrm{EGO} \rightarrow \mathrm{PE}$ & 0.683 & 0.024 \\
\hline
\end{tabular}

\section{Discussion and Conclusions}

An attempt was made in this research to provide a valid and a reliable model for measuring the effectiveness of goal orientation on perceived performance of the players. Therefore, the main concern was delineated to examine a causal association of the said constructs. Confirmatory factor analysis reveals that the model developed along with the data derived from the respondents are theoretically valid enough to proceed with the analysis. The study results reveal that there is a significant association between goal orientation and performance of the players while a significant relationship exists between ego orientation and performance. It is reported that there is no significant association derived from task orientation leading to performance. The results disclosed more ego orientation by the players on the perception of their performance.

Empirical findings of educational research had proven that goal orientation determines students' cognitive and behavioral reactions as well as their educational performance (Barkur, Govindan, \& Kamath, 2013; Hall, Hanna, Hanna, \& Hall, 2015; Barzegar, 2012; Chen \& wong, 2015).

Goal orientation researches which were conducted in the sports context disclosed that male athletes' main concern was to perform better by comparing themselves with other athletes in terms of their abilities in the competitive sports environment (Chin, Khoo, \& Low, 2012; Kleingeld \& Mierlo, 2011). In another study, it was revealed that there is no significant association between goal orientations beliefs and self-appraisals of performance improvement) - When performance is measured by athlete (Van-Yperen \& Duda, 1999).

Research findings based on meta-analysis in the range of year 1989 to 2016, pointed out that those players who are elites most of the time possesses task orientation but team sports athletes are more ego oriented. Additionally, the findings also showed that the players in English speaking countries along with Africa and Middle East and East Asian countries prefer task orientation over ego orientation (Lochbaum, Çetinkalp, Graham, Wright, \& Zazo, 2016)which is partially consistent with the current study.

The study findings of the current research on task orientation is complying with the study conducted Van-Yperen \& Duda (1999), which concluded that there is no significant relationship between task orientation and performance when performance is measured by athletes.

The study findings of the relationship between goal 
orientation and performance had made a valuable impact to the field sports by reporting results of the said relationship. The study additionally conducted to assess the relationship of tak and ego orientation by considering those two facets independently to each other. From this study, it was intended to reveal the goal orientation impact and understand whether it is important for athlete performance and to assess which facets to concentrate over task and ego orientation in order to develop the psychological training programs to enhance performance.

\section{Limitations and Future Research}

The principal limitation of the study is that player's performance was measured based on their perceptions. Undoubtedly, perceptions do not always associate with actuality. This study's methodology did not attempt to measure other variables that might have acted as enablers or barriers to player's performance such as physiological variables(Baker \& Hortan, 2004), environmental factors(Hollings, Hopkins, \& Hume, 2012), factors associated with coach(Perera, 2018) and anthropometric factors are not considered under present study. Furthermore, participants of this study were athletes and hence generalizability to other settings (such as organizational or study setting) should be considered with caution.

Another limitation persist in the present study was that this study was a cross sectional study which the data was collected at one single point. It would be further enriching to obtain data from players before and after a competition and compare the results to obtain a more realistic picture on the influence of goal orientation. Furthermore, the data for this study was collected and analyzed only on team players from team sports. Data can also be collected from individuals from athletic events and a comparative analysis can be done between the individual and team sports players. Moreover the study was a quantitative study based on a self-reported questionnaire. Player's performance can be gained from coaches as well and it is proposed to collect data from the players as well as from coaches on the same construct have better comparison. It is furthermore proposed to extend the research as a blend of qualitative and quantitative so as to validate the relationships based on abstracted empiricism.

\section{REFERENCES}

[1] Al Menhali, E., Khalid, K., \& Iyanna, S. (2018). Testing the psychometric properties of the Environmental Attitudes Inventory on undergraduate students in the Arab context: A test-retest approach. (M. Shahid, Ed.) Psychometric properties of the Environmental Attitudes Inventory in the Arab context, 1-21.
[2] Ames, C. (1992). Classrooms: Goals, structures, and student motivation. Journal of Educational Psychology, 84, 261-271.

[3] Amy E. Daniels, G. S. (2008). Conversion or Conservation? Understanding Wetland Change in North-West Costa Rica. Ecological Society of America.

[4] Anderman, E., \& Maehr, M. (1994). Motivation and schooling in the middle grades. Review of Educational Research, 64, 287-309.

[5] Argyris, C., \& Schön, D. (1997). Organizational Learning: A Theory of Action Perspective. Reis: Revista Española de Investigaciones Sociológicas, 77, 345-348.

[6] Baker, J., \& Hortan, S. (2004). A review of primary and secondary influences on sport expertise. European Council for High Ability, 15(02), 211-227.

[7] Button, S. B., Mathieu, J. E., \& Zajac, D. (1996). Goal orientation in organizational research: A conceptual and empirical foundation. Organizational Behavior \& Human Decision Processes, 67(1), 26-48.

[8] Barkur, R., Govindan, S., \& Kamath, A. (2013, May). Correlation between academic achievement goal orientation and the performance of Malaysian students in an Indian medical school. Educ Health (Abingdon), 26(2), 98-102.

[9] Barzegar, M. (2012). The relationship between Goal Orientation and Academic Achievement- The mediation role of self-regulated learning strategies - a path analysis. International conference on Management, Humanity, and Economics (ICMHE), (pp. 112-115). Phuket.

[10] Besharat, M., \& Pourbohlool, S. (2011). Moderating Effects of Self-Confidence and Sport Self-Efficacy on the Relationship between Competitive Anxiety and Sport Performance. Psychology, 2(7), 70-765.

[11] Biyanwila, B., \& Perera, H. (2018). Associated factors for efficient development of Scool sports system for National level sports in Sri Lanka. Basic and Applied Sciences. 11, p. 29. Colombo: General Sir John Kotelawala Defence University.

[12] Carron, A., Bray, S., \& Eya, M. (2002). Team cohesion and team success in sport. JOURNAL OF SPORTS SCIENCES, 20, 119-126.

[13] Chen, W., \& wong, Y. (2015). The Relationship between Goal Orientation and Academic Achievement in Hong Kong: The Role of Context. Asia-Pacific Edu Res, 24(169).

[14] Chin, N., Khoo, S., \& Low, W. (2012). Self-Determination and Goal Orientation in Track and Field. J Hum Kinet, 33, 151-161.

[15] Duda, J. (1992). Motivation in sports setting: A global perspective approach. In G. Roberts (Ed.), Motivation in sports and exercise. (pp. 57-91). Champaign III: Human Kinetics Books.

[16] Duda, J., \& Nicholls, J. (1992). Dimensions of achievement motivation n schoolwork and sports. Journal of Education Psychology, 8, 290-9.

[17] Duda, J., \& Whitehead, J. (1998). Measurement of goal perspectives in the physical domain. In J. Duda (Ed.), Advances in sports and exercise psychology measurement 
(pp. 21-48). Morgantown, WV.

[18] Duda, J., Fox, K. S., \& Armstrong, N. (1992). Children's Achievement Goals and Beliefs about succes in Sport. British journal of Educational Psychology, 62, 313-23.

[19] Elliot, A., \& McGregor, H. (2001). A 2*2 Achievement Goal Framework. Journal of Personality and Social Psychology, 80, 501-519.

[20] Fornell, C., \& Larcker, D. (1981). Evaluating sructural equation models with unobservable variables and measurement error. Journal of marketing research, 39-50.

[21] Hair, J., Black, W., Babin, B., \& \& Anderson, R. (2010). Multivariate Data Analysis (7th ed.). Upper Saddle River, New Jersey: Prentice Hall.

[22] Hall, M., Hanna, L., Hanna, A., \& Hall, K. (2015, June 25). Associations between Achievement Goal Orientations and Academic Performance among Students at a UK Pharmacy School. Am J Pharm Educ, 79(5).

[23] Heintz, P., \& Steele-Johnson, D. (2004). Clarifying the Conceptual Definitions of Goal Orientation Dimensions: Competence, Control, and Evaluation. Organizational Analysis, 12(1), 5-19.

[24] Heintz, P., Steele-Johnson, D., \& Narayan, A. (2002). Examining state goal orientation effects: A two-dimensional conceptualization. In V. Fortunato (Ed.), An examination of the motivational consequences of goal orientation. Paper presented at the 17th Annual Conference. Toronto: The Society for Industrial and Organizational Psychology.

[25] Hollings, Hopkins, \& Hume. (2012). Environmental and venue-related factors affecting the performance of elite male track athletes. European Journal of Sport Science, 12(3), 201-206.

[26] Kaplan, A., \& Maehr, M. (2007). The Contributions and Prospects of Goal Orientation Theory. Educ Psychol Rev, 19, 141-184.

[27] Kleingeld, A., \& Mierlo, H. A. (2011). The effect of goal setting on group performance. Journal of Applied Psychology, 96, 1289-304.

[28] Lochbaum, M., \& Roberts, G. (1993). Goal Orientations and Perceptions of the Sport Experience. Journal of Sports Exercise Psychology, 15, 160-71.

[29] Lochbaum, M., Çetinkalp, Z., Graham, K., Wright, T., \& Zazo, R. (2016). Task and Ego orientation in competitive Sport: A quantitative review of literature from 1989 to 2016. Kinesiology, 48(1), 3-29.

[30] Nicholls, J. (1984). Achievement motivation: Conceptions of ability, subjective experience, task choice, and performance. Psychological Review, 91, 328-346.

[31] Nicholls, J. (1989). The competitive Ethos and Democratic Education. Cambridge, MA: Harvard University Press.

[32] Nunnally, J., \& Bernstein, L. (1994). Psychometric Theory. New York: McGraw-Hill Higher.

[33] Perera, H. (2018). Factors affecting coach leadership styles and team success: The mediating role of coach leadership behavior. Management Social Ciences and Humanities. 11, p. 40. Colombo: General Sir John Kotelawala Defence University.

[34] Perera, H., \& Pushpakumari, M. (2016). The relationship between Coach Leadership Behavior and Team Success In sports of State universities In Western, Province Sri Lanka. iNCOTeM. 1, pp. 47-51. Colombo: Department of Management of Technology, University of Moratuwa, Katubedda.

[35] Perera, H., \& Pushpakumari, M. (2015). An empirical study of Situational, Leader and Team member characteristics on coach leadership behavior styles Exhibited by the coaches of state Universities in Western Province. International conference on Multidiciplinary Approaches-2015 (ICMA) (p. 158). Colombo: Faculty of Graduate studies, University Of Sri Jayewardenepura.

[36] Perera, H., \& Pushpakumari, M. (2015). The perception of athletes on the factors affecting to coach leadership behavior styles: An empirical study of coach leadership styles exibited by the coaches of State Universities in Western province Sri lanka. International journal of Multidisciplinary studies (IJMS), 2(2), 83-91.

[37] Perera, H., \& Pushpakumari, M. (2015). the perception of Athletes on the Factors Affecting to Coach Leadership Behavior styles: An empirical study on leadership styles Exibited by the Coaches of State Universities in Western Province- Sri Lanka. International Journal of Multidisciplinary Studies (IJMS), 2(2), 83-91.

[38] Perera, H., \& Pushpakumari, M. (2016). THE RELATIONSHIP BETWEEN COACH LEADERSHIP BEHAVIOR AND TEAM SUCCESS IN SPORTS OF STATE UNIVERSITIES IN WESTERN PROVINCE, SRI LANKA. International Conference in Technology Management (iNCOTeM 2016). 1, pp. 47-51. Colombo: University of Moratuwa.

[39] Perera, H., Jusoh, M., Azam, S., \& Sudasinghe, S. (2019). Study of Intrinsic Motivation as a predictor of players' performance in Team Sports. International Journal of Advance Engineering and Research Development, 6(1), 155-157.

[40] Perera, H., Jusoh, M., Azam, S., \& Sudasinghe, S. (2019). The Perceived Significance of Spirituality on Sri Lankan National Team Players' Performance. The Journal of Social Sciences Research, 5(10), 1501-1506.

[41] Perera, H. (2019). Does the Coach Leadership Behavior Mediates the Influence of Factors Affecting Coach Leadership Behavioral Styles on Team Success. International Journal of Human Movement and Sports Sciences, 7(3), 51-57.

[42] Pintrich, P. (2000). The role of goal orientation in self-regulated learning. In M. Boedaerts. In M. Boedaerts, P. Pintrich, \& M. Zeidner (Eds.), Handbook of self-regulation: Theory, research and applications. San Diego, California: Academic.

[43] Roberts, G., Treasure, D., \& Kavussanu, M. (1996). Orthogonality of achievement goals and its relationships to belief about success and satisfaction in sports. The sports psychologist, 10, 398-408.

[44] Sekaran, U. (2003). Research Methods for business (4th ed.). NY: John Wiley \& Sons, Inc. 
[45] Sekaran, U., \& Bougie, R. (2012). Research methods for business (5th ed.). New Delhi: Wiley India.

[46] Sekeran, U., \& Bougie, R. (2010). Research Methods for Business, a skill building approach (5th ed.). Delhi: John Wiley \& Sons Ltd.

[47] Somaratne, G., Nugaliyadda, N., Sagarika, N., Amarasinghe, M., Kahadawarachchi, C., \& Thelijjagada, S. (2014). Enhancing the selection criteria and achievement level in Sri Lankan Sport. PNCTM, 3, 40-44.

[48] Tenenbaum, G., Spence, R., \& Christensen, S. (1999). The Effect of Goal Difficulty and Goal Orientation on Running Performance in Young Female Athletes. Australian Journal of Psychology, 51(1), 6-1.

[49] Vande Walle, D. (1997). Development and validation of a work domain goal orientation instrument. Educational and Psychological Measurement, 8, 995-1015.

[50] Van-Yperen, N., \& Duda, J. (1999). Goal orientations, beliefs about success, and performance improvement among young elite Dutch soccer players. Scand J Med Sci Sporrs, 9, 358-64.

[51] Vella, S., Oades, L., \& Crowe, T. (2013). The relationship between coach leadership, the coach-athlete relationship, team success, and the positive developmental experiences of adolescent soccer players. Physical Education and Sport Pedagogy, 18(5), 549-561.

[52] Willam, L. (1994). Goal orientations and athlete preferences for competence information sources. Journal of Sport and Exercise Psychology, 16, 416-30. 